\title{
Study on the Situation and Teaching Reform Plans of Korean Language Teaching in China in the Context of China-Korea Joint School Running
}

\author{
Jian Zhang Xiangmeng Zhang \\ (International Exchange Center, Tangshan Normal University, Tangshan, 063000, China)
}

\begin{abstract}
In recent years, under education internationalization, with the deepening of bilateral exchanges in economic, political, cultural, and other fields between China and Korea, the Korean language has gradually popularized in higher education in second and third-tier cities in China. Based on the investigation of Korean courses offered by universities in second and third-tier cities in China, this paper analyzes the existing problems in Korean language teaching in the context of China-Korea joint school-running and proposes the corresponding teaching reform plans.
\end{abstract}

Keywords: China-Korea joint school-running; the situation of Korean language teaching; teaching reform

DOI: $10.36012 /$ fhe.v2i1.1569

$\mathrm{W}$

ith the rapid development of the national economy and the demand for "application-oriented" and "compound" talents, large quantities of educational institutions are actively carrying out educational system reform. In recent years, bilateral exchanges between China and Korea in economic, political, cultural and other fields have deepened. Against the backdrop of education internationalization, an increasing number of colleges and $\mathrm{u}-$ niversities in the second and third-tier cities in China have established China-Korea joint education projects. However, due to the short duration of Korean courses, imperfect resources allocation, and lack of systematization as a whole, the teaching mode, teaching method, teaching syllabus and the use of teaching materials need to be improved. Therefore, this paper takes Korean language courses offered in the second and third-tier cities as the research object, analyzes the problems in the teaching process, based on which puts forward the corresponding reform plans.

\section{The Present Situation and Analysis of Ko- rean Language Teaching}

\section{1 .Teaching Mode and Content}

Under the framework of China-Korea cooperation in education, Korean courses generally have a short period yet with heavy teaching tasks, and lectures would be carried out in a large class, whose top priority is to pass level 3 and above in the Test of Proficiency in Korean (TOPIK). Compared with the application of language, teachers focus more on improving students' ability to take examinations. In practical teaching, con- ventional language teaching mode developed under exam-oriented background is generally adopted, which is the "teacher-centered cramming" teaching mode, in which teachers output knowledge unilaterally. A large number of students and the massive task of teaching lead to the conventional teaching mode of "teachers to explain, students to memorize".

In addition, due to the single learning objective, teaching content mainly focuses on the explanation of grammar, vocabulary, and other contents that need to be memorized. Accumulation of vocabulary and the correct use of grammar is centered in the classroom rather than students' ability to apply and communicate with the language. Classroom activities mainly focus on the mechanical application of words and grammatical structures. The lack of the ability of independent creation and practical application of language gradually emerge. Exam-oriented language learning results in the "dumb" state of learners, or the use of typical Chinese-style Korean.

\subsection{Teaching Method}

The currently adopted classroom teaching focuses on teachers' lecturing of teaching content and adopts the conventional four-stage teaching method of "re view, teaching, practice, homework", among which, "teaching" refers to teachers' explanation of basic linguistic knowledge such as pronunciation, vocabulary, grammar, etc., which is the one-way output of teachers' knowledge lacking classroom interaction; "practice" mainly focuses on mechanical exercises, i.e., completing written exercises in teaching materials; "homework" refers to mechanical memory of key content of 
the text, including relevant vocabulary and application of grammatical structure. Due to the tedious teaching content, the lack of novelty in teaching methods, and the lack of interaction in the classroom, students tend to detach themselves from classroom teaching and passively accept knowledge in the state of "audience".

As science and technology develop, multimedia has been applied in classroom teaching. With advantages of convenience, massive information storage and instant display of teaching content, multimedia has been widely used in the teaching process. However, due to various reasons such as limited teaching time of the Korean language curriculum, uneven teaching levels of teachers, the lack of ability to use multimedia resources and the misunderstanding of its application, multimedia is often used as a substitute for blackboard in actual teaching. In the classroom, the content of multimedia courseware is read to students, and knowledge of teaching materials is directly moved to the multimedia screen, failing to give full play to its auxiliary teaching role. Teachers, however, emphasize the diversification of teaching forms ${ }^{[1]}$.

The teaching speed of multimedia usage is faster than that of conventional classroom teaching. Fast switching of courseware content saves a certain amount of time but also shortens the time for students to understand key points, leading to the lack of integrity in students' cognition of learning content ${ }^{[2]}$. The defects mentioned above have resulted in the situation that Korean language teaching has been in the state of "emphasis on 'quantity' rather than 'quality'", "students forget whatever teachers lectured after class".

\subsection{Teaching Materials and Syllabus}

Korean language education in China lacks a language environment, yet schools have not correctly adjusted teaching materials according to the characteristics of joint school-running. In terms of the selection of teaching materials, its applicability is often neglected by schools. Standard selections of teaching materials include textbooks published by Yanbian University, Peking University and other universities, which focus on vocabulary and grammar teaching ${ }^{[3]}$, with the main content of basic knowledge of linguistics such as pronunciation, words and grammar. Although based on daily life, there is little coverage of culture, customs and other humanities aspects, not to mention professional vocabulary and sentence patterns. Apart from this, training in thinking and language application is also insufficient.

As for syllabus, teaching materials lay a direct influence on the composition of the syllabus, as well as on teaching effect. On account of the short course duration, the lack of teaching experience and the discordance with the characteristics of joint school-running, the overall syllabus needs to be improved in terms of systematization and integrity. To be more specific, it lacks detailed explanation in teaching methods, learning content, teaching practice, teachers' role in teaching and emergency responses in the teaching process. Thus, in actual teaching, over-dependent on textbooks, unengaging teaching content, and single teaching method are commonly seen instead of overall understanding of the curriculum structure and thorough explanation and analysis on key points.

\section{The Theoretical Basis of Korean Teaching Reform}

Korean language education has a late start and a low prevalence in foreign language education in China. The majority of research on Korean education take achievements of English education as references, yet, compared with English, most of the learners come into contact with Korean learning after adulthood, which is far later than that of English learning. Therefore, absorbing from English teaching while according to the actual needs of Korean teaching is essential.

On the basis of SLA research results, the "student-centered" English teaching research has attracted wide attention and has been applied to actual classroom teaching. American psychologist Bruner put forward the concept of "student-centered" teaching ${ }^{[4]}$ in the 1960s, the purpose of which is to point out that students should be creative in practicing their language meaningfully, which is helpful to improve their ability to use the knowledge they have learned. S. Pit. Corder once said: effective language learning cannot make students adapt to teachers and textbooks but should make teachers and textbooks adapt to students ${ }^{[5]}$. Carl Ransom Rogers points out that the task of teachers in the classroom is not to teach but to guide, fully embodying the guiding ideology of "student-centered" teaching.

The "learner-centered" language teaching model is established under the guidance of the constructivist learning theory. Constructivism holds that learners are the main body of learning, and learning is a process of 
meaning construction realized through interpersonal cooperation activities with the help of others in a cer tain situation. That is to say, learning should be "learner-centered", and students can acquire knowledge through an organic combination of four learning elements: situation, cooperation, conversation and meaning construction. The "learner-centered" language teaching mode attaches great importance to the exploration of human potential so that students can give full play to their subjective initiative, so as to achieve the purpose of proficient use of language.

In addition, in the 1980s, researchers in second language acquisition and language teaching put forward the task-driven teaching method through bodies of researches and practice based on the constructivist learning theory. "Task-driven" teaching method is different from the conventional "teachers lecturing, students listening", which is a passive teaching mode of teaching and learning, but is a teaching method of "task as the goal, teachers as guiders, students as the main body". It requires the goal of a "task" and the creation of a teaching situation so that students can learn with real tasks while exploration. The "taskdriven" teaching method is in line with the inquiry teaching mode, which is applicable to the cultivation of students' innovation ability and the ability to analyze and solve problems independently.

\section{Teaching Reform Plan}

Korean language education under China-Korea joint school-running aims at nurturing "application-oriented talents" who integrate knowledge into the social life of Korea and adapt to the learning atmosphere in Korean universities, rather than "examination-oriented students". Thus, teaching methods and contents should focus on students' abilities of analytical thinking, problem-solving, and language application rather than merely passing the TOPIK test. As mentioned above, the "student-centered" teaching mode proposed under the guidance of constructivism learning theory aims at tapping students' potential and cultivating their learning autonomy, innovation and language application ability. Therefore, this paper would take the "student-centered" teaching mode as the center, proposing relevant teaching reform programs.

\subsection{Korean Classroom Teaching Under the "Stu- dent-Centered" Teaching Mode}

As the constructivist learning theory emphasizes, un- der the "student-centered" teaching mode, students are the main body of information processing and meaning construction, while teachers act as guides of learning. The amount of knowledge acquired by students does not depend on teachers' output and students' retention but on students' ability to construct the meaning of knowledge according to their own experience. The design of the Korean curriculum should, therefore, leave the creativity of teaching to teachers and return the initiative of learning to students ${ }^{[6]}$, enabling students to internalize knowledge through cooperative activities between teachers and students, instead of applying "cramming" teaching mode to force the infusion of knowledge.

Previous foreign language learning experience reveals that language learning is different from learning other subjects. Only in certain situations can grammar and tone of speech can be understood and mastered ${ }^{[7]}$. Therefore, Korean language teachers should pay attention to situational teaching, combining basic Korean knowledge with scenes, in order to strengthen students' language application ability. As the guider and assistant of learning, by creating scenes and adjusting classroom atmosphere, teachers assist students in connecting learning content with actual life.

In addition, due to the lack of language learning environment in daily life, multimedia such as video and audio materials can be used as auxiliary tools so that students can immerse themselves in the Korean language learning environment.

\subsection{Classroom Interaction by "Discovering-Solv-} ing-Reinforcing" with "Task" as the Mainline

In order to improve students' ability of innovation, independent analysis and problem-solving, Korean language education need to maximize the participation of students in the teaching process. At present, however, most of the Korean courses are taught in large classes with limited teaching timespan, making it impossible for teachers to guide students one by one. One feasible solution is to divide the students into several groups to complete learning tasks so as to improve the participation of students in the teaching process. The authors have tried to use the teaching method of "discovering-solving-reinforcing" to let students participate in the whole process of learning. The specific steps are as follows:

3.2.1 "Discovering": leading in and determining the problem. Students are organized to understand the 
text as a whole and introduced with tasks around the text. After that, students are allowed to express their own opinions around assigned tasks and refine val uable questions. This stage requires students to be well prepared before class.

3.2.2 "Solving": tackling questions discovered in the previous stage and meaning configuration is achieved through cooperation in this stage. Students are guided to explore the inner connection among learning content by way of group discussion based on their own experience, in order to complete the meaning construction independently. afterwards, conclusions are reported by groups, and teachers make supplement and evaluation accordingly. As the guide and assistant, teachers need to take into consideration the setting of the situation, helping students exploring and acquiring knowledge, completing the meaning configuration.

3.2.3 "Reinforcing": Completing exercises in certain situations. At this stage, the focus of practice is not on students' mechanized practice of vocabulary and grammar but on application-oriented exercises that meet the situation settings, which can be displayed to students with pictures, photos, or small images materials through multimedia. Students can use this as the background and carry out situational exercises in groups, and each holds its own responsibility and create freely, showing results in various forms such as essays and sitcoms. As a learning assistant, teachers should summarize and evaluate the final practice results, or organize students to carry out the intergroup evaluation, point out advantages and disadvantages, so as to deepen comprehension of knowledge.

\subsection{Compile Relevant Teaching Materials Accord- ing to Teaching Characteristics}

Teaching materials determine the content of teaching and affect the design of the teaching syllabus. The selection of teaching materials directly affects the quality and difficulty of teaching. The textbooks compiled with examination-oriented focus are not conducive to application ability training. As the basis of teaching reform, teaching material reform should be conducted in the first place. According to the characteristics of China-Korea joint school running, bold innovations are required by referencing classical textbooks. Korean language teaching materials should closely related to Korean social life, campus life and cultural background.
The vocabulary part should be divided into basic vocabulary and expanded vocabulary. The basic vocabulary should be appropriate in difficulty, and professional words and phrases should be added to the expanded vocabulary. Grammar should be introduced systematically (e.g., clear labeling of colloquial style and formal style). In addition, innovative thinking training should be added to after-class practice so as to achieve the effect of students' language-thinking two-way training ${ }^{[8]}$.

\section{Conclusion}

Under the background of China-Korea joint school running, the teaching reform of basic Korean language courses requires effort from schools and teachers, starting from the actual needs of students' overseas professional study, daily life and employment issues. By exploring and solving problems in the actual teaching process, we can make the course design more reasonable, teaching materials more in line with actual needs, and teaching methods more diversified, and therefore to promote teaching reform and to refine the basic Korean language curriculum.

\section{Reference}

[1] Xiao Ting. Analysis of the advantages and disadvantages of multimedia-assisted teaching in Korean teaching in colleges and universities [J]. Innovation Education, 2015 (18): 1673-0208.

[2] Nie Hongyi. Analysis of the advantages and disadvantages of Korean teaching in multimedia-as sisted universities [J]. Contemporary Teaching and Re search Series, 2018 (06): 2095-6517.

[3] Cui Hongnan. On the current situation of Korean language teaching and improvement plan [J]. Journal of Heilongjiang Vocational College of Ecological Engineering, 2010 (05): 1674-6341.

[4] Bruner Jerome Seymour. The Process of Education [M]. LINDON: HARVARD UNIVERSITY PRESS, 1960.

[5] Corder S. Pit. The Language of Second - Language Learners: The Broader Issues [J].The Modern Language Journal, (1975), 59(8):409-413.

[6] Wang Xiuwei. "Student-centered" basic Korean language teaching model reform [J]. Journal of Nanchang College of Education,2013 (07): 1008-6757.

[7] Liu Xuyan, Pan Deng. "Student-centric" basic Korean language teaching model reform research $[\mathrm{J}]$. Curriculum education research,2016 (03): 2095-3089.

[8] Shi Shichan. Research on the Teaching Reform of the Second Foreign Language Korean Curriculum-Taking Guizhou University for Nationalities as an Example [J]. Popular Literature, 2019 (14): 1007-5828 